\section{BMJ Open \\ Respiratory \\ Research}

\section{Perceptions of medical students towards antibiotic prescribing for upper respiratory tract infections in Saudi Arabia}

To cite: Harakeh S, Almatrafi M, Ungapen $\mathrm{H}$, et al. Perceptions of medical students towards antibiotic prescribing for upper respiratory tract infections in Saudi Arabia. BMJ Open Resp Res 2015;2: e000078. doi:10.1136/ bmjresp-2014-000078

Received 30 December 2014 Revised 20 April 2015 Accepted 21 April 2015

\section{CrossMark}

For numbered affiliations see end of article.

Correspondence to Professor Steve Harakeh; Sharakeh@gmail.com

\section{ABSTRACT}

Introduction: This survey evaluates knowledge, attitudes and practices of medical students towards use of antibiotics for upper respiratory infections (URTIs).

Methodology: Cross-sectional questionnaire study among 1042 randomly selected medical students in Saudi Arabia.

Results: Respondents were mostly Saudis (97.5\%), had previous knowledge of antibiotics (99.7\%) and their usage $(98.3 \%)$ against bacterial infections $(93.7 \%) .18 .1 \%$ thought that they could be used for viral infections. Nearly all students $(97.2 \%)$ used antibiotics themselves during the previous year and self-medication without a prescription was high at $49 \%$ of cases. Most antibiotics were taken for URTI symptoms $(61.8 \%)$. Female medical students had better knowledge on antibiotic effectiveness against bacteria and viruses, and overall knowledge increased with study year. Health seeking behaviour rates for symptoms of RTI and associated estimated necessity for antibiotics varied but were highest for cough with yellow/green phlegm.

Conclusions: The depth of knowledge that healthcare professionals have in relation to the proper use of antibiotics is essential in spreading the right message within communities. This is the first large study among medical students in Saudi Arabia, shedding important light on areas for improvement in the medical curriculum as well as antibiotic practices of medical students themselves.

\section{INTRODUCTION}

Upper respiratory tract infections (URTIs) are defined as illnesses caused by an acute infection involving the upper respiratory tract, such as the nose, sinuses, pharynx and/or larynx. ${ }^{1}$ They cause diseases such as the common cold and tonsillitis. They are considered the most common infections in
Saudi Arabia. ${ }^{2-4}$ Most URTIs are viral and self-limiting and do not need antibiotic treatment. $^{5} 6$

The improper and excessive use of antibiotics has resulted in the emergence of highly resistant bacteria. In developing countries, including Saudi Arabia, antibiotics are excessively prescribed and can be obtained, in many instances, without a prescription. Apart from patients' perceptions and expectations, ${ }^{7}$ knowledge held by healthcare professionals is a major determinant with regard to the prescription of antibiotics. The depth of knowledge healthcare professionals have in relation to the proper use of antibiotics is essential in spreading the right message within communities. A doctor or a medical graduate student undergoes excessive training to be able to prescribe antibiotics. Medical students are the future of medicine and one of the pillars of healthcare. Their beliefs, attitudes and behaviours regarding the use of antibiotics have a tremendous impact on the consequences associated with such uses in Saudi Arabia. For this reason, it is important to evaluate their knowledge, attitudes and practices towards antibiotics' use, specifically in the treatment of URTIs. Based on the above, this study was undertaken to assess the knowledge, attitudes and practices of Saudi Arabian medical students towards the use of antibiotics in the treatment of URTIs. In Saudi Arabia, medical school consists of 6 years. During the first 3 years, students take courses related to basic sciences. This is followed by another 3 years where students study clinically related courses and do their rotations in the different fields of medicine. 


\section{METHODOLOGY}

We performed a cross-sectional study among medical students in the two universities, Umm Alqura University, Makkah (UQU), and King Abdulaziz University (KAU), in Saudi Arabia, in 2013, using a paper-based questionnaire. Respondents were randomly selected from the venue of the medical school building and its surrounding university-associated hospital, and were interviewed by one of our trained data collectors.

We asked 20 questions with subitems with different response options including multiple choice, Likert-type scale response items, and dichotomised yes or no options. We developed the survey based on previously published international qualitative and quantitative scientific surveys. ${ }^{8} 9$ Ethical approval was obtained from KAU ethical committee and participants signed a consent form before participating.

We entered all results into a SPSS 20.0 data file. The records were double-checked and cleaned by two researchers. Data were then analysed using descriptive statistics. $\chi^{2}$ Test were performed to identify associations between variables such as gender, year of study, agreement with the principle of antibiotic resistance and previous antibiotic use; as well as accurate knowledge of antibiotic effectiveness against bacteria but not against viruses.

\section{RESULTS}

\section{Demographics}

As respondents were randomly contacted within the premises of their university medical faculties, 1500 medical students were approached and 1042 of them agreed to participate (response rate 69.5\%). Of these, $97.5 \%$ were Saudis and $47.3 \%$ were male. The majority $(57.5 \%)$ of respondents were older than 21, but younger than 24 years of age. All were medical university students, more or less equally distributed among the 2nd to 6 th year of schooling, with only $7.4 \%$ still in their first year. They were distributed UQU (56.8\%) and KAU $(43.2 \%)$ (table 1$)$.

\section{Knowledge, attitudes and practice}

The majority of respondents indicated that they had previous knowledge of antibiotic agents $(99.7 \%)$ and of their usage $(98.3 \%)$. Only $86.6 \%$ of them, however, correctly identified penicillin as an antibiotic, while 51.8\% did not know whether codeine was an antibiotic or not. While $93.7 \%$ knew that antibiotics should be used in the treatment of bacterial infections, $18.1 \%$ thought that they may also be used in the treatment of viral infections. When these two questions were combined, $75.0 \%$ of respondents correctly stated that antibiotics are effective against bacterial but not against viral infections (table 2).

Of the respondents, $97.2 \%$ had used antibiotics during the past year. Of these medicines, $51 \%$ were obtained through a doctor's prescription. Most of them, $61.8 \%$ of
Table 1 Characteristics of the study population $(n=1042)$ (always put tables outside of text. Insert at end of main text or as separate file)

\begin{tabular}{lc}
\hline Demographics & $\begin{array}{l}\text { Respondents } \\
\mathbf{n}(\%)\end{array}$ \\
\hline Gender & \\
Males & $493(47.3)$ \\
Females & $549(52.7)$ \\
Age groups & \\
$18-20$ & $280(26.9)$ \\
$21-23$ & $599(57.5)$ \\
$24-26$ & $162(15.6)$ \\
Nationality & $1016(97.5)$ \\
Saudi Arabia & $26(2.5)$ \\
Others & \\
University & $592(56.8)$ \\
$\quad$ Umm Alqura & $450(43.2)$ \\
King Abdulaziz & \\
\hline
\end{tabular}

cases, were used for a RTI. In the past year, $87.1 \%$ of respondents had obtained some information on antibiotics from one source or another. Among the top three sources of information cited were doctors $(43.6 \%)$, followed by the internet $(41.2 \%)$ and 'other sources' $(47.2 \%)$, which was the most common answer, ahead of the other choices given to respondents, namely:

Table 2 Respondents' knowledge, beliefs and experiences of antibiotics $(n=1042)$

\begin{tabular}{|c|c|c|}
\hline \multicolumn{2}{|c|}{ Knowledge, beliefs and experiences } & \multirow{2}{*}{$\begin{array}{l}\text { Agree } \\
\text { n (\%) } \\
782(75.0)\end{array}$} \\
\hline Knowledge & $\begin{array}{l}\text { Antibiotics are effective in } \\
\text { treating bacterial but not } \\
\text { viral infections }\end{array}$ & \\
\hline & $\begin{array}{l}\text { Antibiotics are effective in } \\
\text { treating bacterial infections }\end{array}$ & 976 (93.7) \\
\hline & $\begin{array}{l}\text { Antibiotics are effective in } \\
\text { treating viral infections }\end{array}$ & $188(18.1)$ \\
\hline \multirow[t]{7}{*}{$\begin{array}{l}\text { Beliefs and } \\
\text { Experiences }\end{array}$} & $\begin{array}{l}\text { I usually know when I need } \\
\text { antibiotics }\end{array}$ & 717 (68.9) \\
\hline & $\begin{array}{l}\text { My doctor's obligated to } \\
\text { prescribe antibiotics on my } \\
\text { request }\end{array}$ & $129(12.4)$ \\
\hline & $\begin{array}{l}\text { It is easy to obtain } \\
\text { antibiotics }\end{array}$ & 737 (70.9) \\
\hline & $\begin{array}{l}\text { Decisions regarding the } \\
\text { prescription of antibiotics } \\
\text { should only be taken by a } \\
\text { specialist doctor }\end{array}$ & 836 (80.2) \\
\hline & $\begin{array}{l}\text { Doctors should not be } \\
\text { hasty in prescribing } \\
\text { antibiotics }\end{array}$ & $987(95.1)$ \\
\hline & $\begin{array}{l}\text { It is acceptable to stop a } \\
\text { course of antibiotics as } \\
\text { soon as symptoms resolve }\end{array}$ & 225 (21.6) \\
\hline & $\begin{array}{l}\text { Bacteria can become } \\
\text { resistant to antibiotics }\end{array}$ & $990(95.0)$ \\
\hline
\end{tabular}


Table 3 Respondents' perceived need for antibiotic treatment, perceived need to consult a doctor for respiratory tract symptoms and perceived need for antibiotic treatment for RTIs $(n=1042)$

\begin{tabular}{lll}
\hline Symptoms and RTIs & $\begin{array}{l}\text { Perceived need for antibiotic } \\
\text { treatment (always/often) } \\
\mathbf{n}(\%)\end{array}$ & $\begin{array}{l}\text { Perceived need to consult } \\
\text { a doctor (always/often) } \\
\mathbf{n}(\%)\end{array}$ \\
\hline $\begin{array}{l}\text { Symptoms } \\
\text { Throat congestion }\end{array}$ & $383(36.8)$ & $274(26.3)$ \\
Nose congestion with headache & $219(21.0)$ & $232(22.3)$ \\
Cough with transparent phlegm & $139(13.4)$ & $213(20.4)$ \\
Cough with yellow/green phlegm & $753(72.3)$ & $537(51.6)$ \\
Cough with fever & $607(58.3)$ & $449(43.1)$ \\
Cough lasting more than 2 weeks & $615(59.1)$ & $628(60.3)$ \\
RTls & $153(14.7)$ & NA \\
Common cold and or flu & $664(63.9)$ & \\
Acute bronchitis & $861(82.9)$ & \\
Pneumonia & &
\end{tabular}

pharmacists, drugstores, leaflets/publications related to a disease or a health condition, medicine notice/leaflet and the media (television, newspapers or magazines). Those who answered 'other sources' reported that medical textbooks were their source of knowledge.

Where RTI symptoms were mentioned, the perceived need to consult with a doctor ranged from $60.3 \%$ for a continuous cough lasting 2 weeks, to $20.4 \%$ for a cough with clear phlegm. On the other hand, the perceived need for taking antibiotics was $72.3 \%$ for a cough with yellow phlegm, and $13.4 \%$ for a cough with clear phlegm (table 3).

\section{Variables associated with accurate knowledge of antibiotic effectiveness}

Bivariate analysis of the data indicated that women had better knowledge of the effectiveness of antibiotics against bacteria but not against viruses (table 4). Knowledge of the effectiveness of antibiotics steadily rose with the year of study. Finally, those who acknowledged the emergence of developing bacterial resistance were more likely to have accurate knowledge on antibiotic effectiveness.

On the other hand, no significant associations were noted between knowledge of the effectiveness of antibiotics and previous use of antibiotics $(\mathrm{p}=0.097)$, previous prescription of antibiotics within the year $(\mathrm{p}=0.987)$ or previous prescription of antibiotics for respiratory infections within the year $(p=0.457)$.

\section{DISCUSSION}

In this large questionnaire study, we identified that Saudi Arabian medical students have extensive experience in using antibiotics for URTI themselves, but knowledge on antibiotic effectiveness vary widely with differences in gender and years of experience as medical student. Practices to obtain antibiotics without a prescription are also common among medical students themselves.

\section{LIMITATIONS AND STRENGTHS}

The study's limitations lay in that it was conducted among medical students in two big universities in the western region of Saudi Arabia. As such, the study population inherently showed a high knowledge of the use of antibiotics. Students from other disciplines as well as the population at large may have different levels of knowledge in relation to the subject at hand. Currently, a study is being conducted to evaluate the knowledge, attitudes and behaviour regarding the use of antibiotics among the public in Saudi Arabia. In the future, it would be interesting to expand the study to include rural communities from different regions of Saudi Arabia to be able to formulate specific recommendations to target and inform the public.

On the other hand, this study managed to include more than 1000 participants, which marks the first time for a study of such scale to be conducted in Saudi Arabia. This is an important study as it sheds the light on the knowledge, attitude and behaviours of a highly

Table 4 Factors significantly associated with accurate knowledge of antibiotics' effectiveness (782 of 1042 who had accurate knowledge)

\begin{tabular}{lcll}
\hline Factors & Accurate knowledge & OR & p Value \\
\hline Gender & & & \\
Males & $349(70.8 \%)$ & - & 0.003 \\
Females & $433(78.9 \%)$ & 1.540 & \\
Study year & & & \\
1st & $22(28.6 \%)$ & - & 0.001 \\
2nd & $95(54.6 \%)$ & 3.006 & \\
3rd & $130(65.7 \%)$ & 4.779 & \\
4th & $158(84.9 \%)$ & 14.107 & \\
5th & $195(92.4 \%)$ & 30.469 & \\
6th & $182(92.9 \%)$ & 32.500 & \\
Bacterial resistance to antibiotics & & \\
Agree & $764(77.2 \%)$ & 6.385 & 0.000 \\
Disagree & $18(34.6 \%)$ & - & \\
\hline
\end{tabular}


specialised section of the Saudi community, namely, future doctors, who will be responsible for the prescription of antibiotics for years to come.

\section{Knowledge, attitudes and practices}

The data on the use of antibiotics against bacterial and not viral infections, and on the need to complete the course of treatment to reduce antimicrobial resistance, are much higher than what has been reported in a survey on the public in the Netherlands. ${ }^{8}$ The medical background of our participants may account for those differences. Those who answered incorrectly were mostly first year students who had not received courses related to antibiotics, similar to findings of a large study among Chinese students. ${ }^{9}$ The results on the need for careful prescription of antibiotics by a physician are in contrast to those of an Italian study that reported that $22.7 \%$ of their respondents were willing to take an antibiotic without doctor's prescription. ${ }^{10}$ Again, the medical background of our study population could explain this. Bacterial resistance to antibiotics was indicated among our study group and only a small percentage thought it acceptable to stop the course of antibiotics as soon as the symptoms subside, and the participants were aware of the adverse effects associated with the excessive and improper use of antibiotics in the emergence of bacterial resistance.

Obtaining antibiotics over the counter, without a physician's prescription, has been a common practice in developing countries and is consistent with other studies. ${ }^{11}$ The familiarity of our respondents with the different antibiotics is due to their medical background and is contrary to the results from an Italian study that indicated some superficiality in the knowledge of antibiotics and resistance. ${ }^{10}$ In a study conducted in the UK, final year medical students were given the names 'Ciproxin' and 'ciprofloxacin' as an example, and were asked to name six generic or approved antibiotics by their proprietary name. Sixty per cent of them only knew the generic names for Augmentin and Fucidin, $40 \%$ were correct on Flagyl and 10\% on Zinacef, but none had the correct generic name for either Targocid or Magnapen. ${ }^{12}$ In another study conducted in Malaysia, also on final year medical and pharmacology students, diphenhydramine was correctly identified by $97 \%$ of the students as the antibiotic used for treatment of URIs, while only $75.6 \%$ correctly identified that cefotaxime belonged to third-generation cephalosporins. ${ }^{13}$ The patient's pressure on their doctors to prescribe antibiotics were similar to others. ${ }^{14}$ This is especially true among the middle-income and low-income settings, as reported in a study in Peru, ${ }^{15}$ and among parents and paediatricians in Venezuela, where $87 \%$ of doctors felt pressured by parents into prescribing antibiotics. ${ }^{16}$

Health seeking behaviour rates for symptoms of RTI and the associated estimated necessity for antibiotics were slightly lower than what has been reported elsewhere and again a reflection of the medical background of the study population. ${ }^{8}$ Our respondents thought that antibiotics should always be prescribed when experiencing cough with yellow/clear phlegm. This is a misconception, and a reflection of wrong knowledge among our respondents, which is not consistent with the results obtained by others. ${ }^{8}$

\section{Other studies in low-income and middle-income countries}

Studies conducted in many developing countries, including Palestine and southwest Nigeria, have indicated that people rely on the advice of their 'medical' friends to self-medicate. ${ }^{17} 18$ In addition, in many instances, people reported copying a doctor's prescription without a second consultation with a physician or without the need for a fresh prescription. In contrast to this, respondents in this study stated that they relied on their doctors for the prescription of antibiotics. Also, the same was reported in other published studies. ${ }^{11}$

Being in the medical field, participants to this study had a good background in relation to the time to start antibiotics treatment. These findings are consistent with what has been reported by others. ${ }^{9} 1920$

Older students were more likely to be knowledgeable in relation to antibiotics' effectiveness. This is consistent with what has been reported by others in a study among Chinese medical students, which indicated that the students' knowledge improved as they progressed in their study, attaining the highest scores at third and fourthyears, suggesting that the medical curriculum enhanced their understanding of antibiotics use. Similarly, their attitude on the use of antibiotics was only slightly improved (year 4) over the same period with a clearer recognition of antibiotic abuses and development of drug resistance in bacteria. ${ }^{9}$ The reason behind this could be that courses on medical microbiology are not given during the first year. Another reason could be that other relevant courses, such as pharmacology, internal medicine and epidemiology, also are not provided to students during their first year of medical school. The increase of knowledge of participants with their years of study would indicate that their cumulative curricula enhanced their knowledge about antibiotics usage and the dangers of encountering resistance. This is contrary to the findings of a study conducted on house staff physicians at the Johns Hopkins University Hospital in Baltimore, which showed that physicians had a suboptimal knowledge about antimicrobials, and their knowledge was not enhanced over the course of their training. ${ }^{21}$

The results showed that young women had more accurate knowledge of antibiotics' effectiveness than young men $\operatorname{did}(p=0.003)$. In Saudi society, women are more inclined to spend time with their mothers and be involved in raising children. As such, they become more aware of the medications children take and the diseases they encounter throughout their childhood. This is consistent with what has previously been reported by others who also found that women consult more frequently, often with their children, and therefore receive more accurate information on antibiotics; however, the finding 
that women had more accurate knowledge was independent of having children in the household in that study. ${ }^{8}$

\section{CONCLUSION}

The knowledge on antibiotic effectiveness varies widely with differences in gender and years of experience as medical student in this large study among medical students in Saudi Arabia. Self-medication of antibiotics without a prescription is common among students in Saudi Arabia, which is worrying. The results may shed important light on areas for improvement in the medical curriculum as well as antibiotic practices of medical students themselves.

\section{Author affiliations}

${ }^{1}$ Special Infectious Agents Unit, King Fahd Medical Research Center, King Abdulaziz University, Jeddah, Saudi Arabia

${ }^{2}$ Obstetrics and Gynecology Department, King Abdulaziz Medical City, National Guard Health Affair, Riyadh, Saudi Arabia

${ }^{3}$ Manchester, UK

${ }^{4}$ Department of Pediatric, King Fahad Armed Forces Hospital, Jeddah, Saudi Arabia

${ }^{5}$ Medical School, Umm Alqura University, Makkah, Saudi Arabia

${ }^{6}$ Department of Family Medicine, National Guard Hospital, Jeddah, Saudi Arabia

${ }^{7}$ Department of Pediatric, National Guard Hospital, Jeddah, Saudi Arabia

${ }^{8}$ Biology Department, King Abdulaziz University, Jeddah, Saudi Arabia

${ }^{9}$ Department of Animal and Veterinary Sciences, American University of Beirut, Lebanon; Adjunct to Biochemistry Department, Faculty of Science and Production of Bioproducts for Industrial Application Research Group, King Abdulaziz Univeristy, Jeddah, Saudi Arabia

${ }^{10}$ King Fahd Medical Research Center, Jeddah, Saudi Arabia

${ }^{11}$ Department of Gastroenterology, Faculty of Medicine, King Abdulaziz University, Jeddah, Saudi Arabia

${ }^{12}$ Biochemistry Department, Faculty of Science and Experimental Biochemistry Unit, King Fahd Medical Research Center, Jeddah, Saudi Arabia

${ }^{13}$ Department of Interdisciplinary Social Science, Utrecht University, Utrecht, The Netherlands

${ }^{14}$ Drug Metabolism Unit, King Fahd Medical Research Center, Jeddah, Saudi Arabia

${ }^{15}$ Department of Family Medicine, School of Primary Care and Public Health (CAPHRI), Maastricht University, Maastricht, The Netherlands

Competing interests None declared.

Ethics approval The University Ethical Committee.

Provenance and peer review Not commissioned; externally peer reviewed.

Data sharing statement No additional data are available.

Open Access This is an Open Access article distributed in accordance with the Creative Commons Attribution Non Commercial (CC BY-NC 4.0) license, which permits others to distribute, remix, adapt, build upon this work noncommercially, and license their derivative works on different terms, provided the original work is properly cited and the use is non-commercial. See: http:// creativecommons.org/licenses/by-nc/4.0/

\section{REFERENCES}

1. Eccles MP, Grimshaw JM, Johnston M, et al. Applying psychological theories to evidence-based clinical practice: identifying factors predictive of managing upper respiratory tract infections without antibiotics. Implement Sci 2007;2:26.

2. Sabra SM, Omar SR, Abdel-Fattah MM. Surveillance of Some common infectious diseases and evaluation of the control measures used at Taif, KSA (2007-2011). Middle-East J Sci Res 2012;11:709-17.

3. Alghamdi AA, Alamoudi OS, Ghabrah TM. Pattern of infectious diseases in the western region of Saudi Arabia; a study of 495 hospitalized patients. J King Abdulaziz Univ Med Sci 2009;16:3-15.

4. Chowdhury MN. Empiric therapy of common bacterial infections in Saudi Arabia; a review. J Hyg Epidemiol Microbiol Immunol 1992;36:63-84.

5. Gonzales R, Malone DC, Maselli JH, et al. Excessive antibiotic use for acute respiratory infections in the United States. Clin Infect Dis 2001;33:757-62.

6. Heikkinen T, Järvinen A. The common cold. Lancet 2003;361:51-9.

7. Alumran $\mathrm{A}, \mathrm{Hou} \mathrm{XY}$, Hurst $\mathrm{C}$. Assessing the overuse of antibiotics in children in Saudi Arabia: validation of the parental perception on antibiotics scale (PAPA scale). Health Qual Life Outcomes 2013;11:1-8.

8. Cals JWL, Boumans D, Lardinois RJM, et al. Public beliefs on antibiotics and respiratory tract infections: an internet-based questionnaire study. Br J Gen Pract 2007;57:942-7.

9. Huang $\mathrm{Y}, \mathrm{Gu} J$, Zhang M, et al. Knowledge, attitude and practice of antibiotics: a questionnaire study among 2500 Chinese students. BMC Med Educ 2013;13:163.

10. Napolitano F, Izzo MT, Di Giuseppe G, et al. Public knowledge, attitudes, and experience regarding the use of antibiotics in Italy. PLOS ONE 2013;8:e84177.

11. Widayati A, Suryawati S, de Crespigny C, et al. Beliefs about the use of nonprescribed antibiotics among people in Yogyakarta City, Indonesia: a qualitative study based on the theory of planned behavior. Asia Pac J Public Health 2015;27:NP402-13.

12. Wright EP, Jain P. Survey of antibiotic knowledge amongst final year medical students. J Antimicrob Chemother 2004;53:550-1.

13. Jamshed $S Q$, Elkalmi $\mathrm{R}$, Rajiah $\mathrm{K}$, et al. Understanding of antibiotic use and resistance among final-year pharmacy and medical students: a pilot study. J Infect Dev Ctries 2014;8:780-5.

14. Thriemer K, Katuala Y, Batoko B, et al. Antibiotic prescribing in DR Congo: a knowledge, attitude and practice survey among medical doctors and students. PLOS ONE 2013;8:e55495.

15. García C, Llamocca LP, García K, et al. Knowledge, attitudes and practice survey aboutantimicrobial resistance and prescribing amongphysicians in a hospital setting in Lima, Peru. BMC Clin Pharmacol 2011;11:18.

16. ML NL, Martin A. Influencia de los padres en la prescripcion de antibioticos hecha por los pediatras. Arch Venez Pueric Pediatr 2002;65:21-7.

17. Sapkota AR, Coker ME, Goldstein RER, et al. Self-medication with antibiotics for the treatmentof menstrual symptoms in southwest Nigeria: across-sectional study. BMC Public Health 2010;10:610.

18. Sawalha AF. Self-medication with antibiotics: a study in Palestine. Int J Risk Saf Med 2008;20:213-22.

19. Dyar OJ, Pulcini C, Howard P, et al. European medical students: a first multicentre study of knowledge, attitudes and perceptions of antibiotic prescribing and antibiotic resistance. J Antimicrob Chemother 2014;69:842-6.

20. Bala R, Singh H, Kaur K. Knowledge and attitude towards antimicrobial self medication usage: a cross sectional study among medical and nursing students. Int J Basic Clin Pharmacol 2013;2:428-32.

21. Srinivasan A, Song X, Richards A, et al. A survey of knowledge, attitudes, and beliefs of house staff physicians from various specialties concerning antimicrobial use and resistance. Arch Intern Med 2004;164:1451-6. 


\section{BMJ Open Respiratory Research}

\title{
Perceptions of medical students towards antibiotic prescribing for upper respiratory tract infections in Saudi Arabia
}

\author{
Steve Harakeh, ${ }^{1}$ Musab Almatrafi, ${ }^{2}$ Haifa Ungapen, ${ }^{3}$ Rotana Hammad, ${ }^{4}$ \\ Feras Olayan, ${ }^{5}$ Reema Hakim, ${ }^{6}$ Mohammed Ayoub, ${ }^{7}$ Noura Bakhsh, ${ }^{5}$ \\ Saad B Almasaudi, ${ }^{8}$ Elie Barbour, ${ }^{9}$ Suhad Bahijri, ${ }^{10}$ Esam Azhar, ${ }^{1}$ \\ Ghazi Damanhouri, ${ }^{10}$ Yousef Qari, ${ }^{11}$ Taha Kumosani, ${ }^{12}$ Zeena Harakeh, ${ }^{13}$ \\ Muhammad S Ahmad, ${ }^{14}$ JochenW L Cals ${ }^{15}$
}

To cite: Harakeh S, Almatrafi M, Ungapen $\mathrm{H}$, et al. Perceptions of medical students towards antibiotic prescribing for upper respiratory tract infections in Saudi Arabia. BMJ Open Resp Res 2015;2: e000078. doi:10.1136/ bmjresp-2014-000078

Received 30 December 2014 Revised 20 April 2015 Accepted 21 April 2015

\section{CrossMark}

For numbered affiliations see end of article.

Correspondence to Professor Steve Harakeh; Sharakeh@gmail.com

\section{ABSTRACT}

Introduction: This survey evaluates knowledge, attitudes and practices of medical students towards use of antibiotics for upper respiratory infections (URTIS). Methodology: Cross-sectional questionnaire study among 1042 randomly selected medical students in Saudi Arabia.

Results: Respondents were mostly Saudis (97.5\%), had previous knowledge of antibiotics (99.7\%) and their usage $(98.3 \%)$ against bacterial infections $(93.7 \%) .18 .1 \%$ thought that they could be used for viral infections. Nearly all students (97.2\%) used antibiotics themselves during the previous year and self-medication without a prescription was high at $49 \%$ of cases. Most antibiotics were taken for URTI symptoms (61.8\%). Female medical students had better knowledge on antibiotic effectiveness against bacteria and viruses, and overall knowledge increased with study year. Health seeking behaviour rates for symptoms of RTI and associated estimated necessity for antibiotics varied but were highest for cough with yellow/green phlegm.

Conclusions: The depth of knowledge that healthcare professionals have in relation to the proper use of antibiotics is essential in spreading the right message within communities. This is the first large study among medical students in Saudi Arabia, shedding important light on areas for improvement in the medical curriculum as well as antibiotic practices of medical students themselves.

\section{INTRODUCTION}

Upper respiratory tract infections (URTIs) are defined as illnesses caused by an acute infection involving the upper respiratory tract, such as the nose, sinuses, pharynx and/or larynx. ${ }^{1}$ They cause diseases such as the common cold and tonsillitis. They are considered the most common infections in
Saudi Arabia. ${ }^{2-4}$ Most URTIs are viral and self-limiting and do not need antibiotic treatment. $^{56}$

The improper and excessive use of antibiotics has resulted in the emergence of highly resistant bacteria. In developing countries, including Saudi Arabia, antibiotics are excessively prescribed and can be obtained, in many instances, without a prescription. Apart from patients' perceptions and expectations, ${ }^{7}$ knowledge held by healthcare professionals is a major determinant with regard to the prescription of antibiotics. The depth of knowledge healthcare professionals have in relation to the proper use of antibiotics is essential in spreading the right message within communities. A doctor or a medical graduate student undergoes excessive training to be able to prescribe antibiotics. Medical students are the future of medicine and one of the pillars of healthcare. Their beliefs, attitudes and behaviours regarding the use of antibiotics have a tremendous impact on the consequences associated with such uses in Saudi Arabia. For this reason, it is important to evaluate their knowledge, attitudes and practices towards antibiotics' use, specifically in the treatment of URTIs. Based on the above, this study was undertaken to assess the knowledge, attitudes and practices of Saudi Arabian medical students towards the use of antibiotics in the treatment of URTIs. In Saudi Arabia, medical school consists of 6 years. During the first 3 years, students take courses related to basic sciences. This is followed by another 3 years where students study clinically related courses and do their rotations in the different fields of medicine. 


\section{METHODOLOGY}

We performed a cross-sectional study among medical students in the two universities, Umm Alqura University, Makkah (UQU), and King Abdulaziz University (KAU), in Saudi Arabia, in 2013, using a paper-based questionnaire. Respondents were randomly selected from the venue of the medical school building and its surrounding university-associated hospital, and were interviewed by one of our trained data collectors.

We asked 20 questions with subitems with different response options including multiple choice, Likert-type scale response items, and dichotomised yes or no options. We developed the survey based on previously published international qualitative and quantitative scientific surveys. ${ }^{8} 9$ Ethical approval was obtained from KAU ethical committee and participants signed a consent form before participating.

We entered all results into a SPSS 20.0 data file. The records were double-checked and cleaned by two researchers. Data were then analysed using descriptive statistics. $\chi^{2}$ Test were performed to identify associations between variables such as gender, year of study, agreement with the principle of antibiotic resistance and previous antibiotic use; as well as accurate knowledge of antibiotic effectiveness against bacteria but not against viruses.

\section{RESULTS}

\section{Demographics}

As respondents were randomly contacted within the premises of their university medical faculties, 1500 medical students were approached and 1042 of them agreed to participate (response rate $69.5 \%$ ). Of these, $97.5 \%$ were Saudis and $47.3 \%$ were male. The majority $(57.5 \%)$ of respondents were older than 21, but younger than 24 years of age. All were medical university students, more or less equally distributed among the 2nd to 6 th year of schooling, with only $7.4 \%$ still in their first year. They were distributed UQU (56.8\%) and KAU $(43.2 \%)$ (table 1$)$.

\section{Knowledge, attitudes and practice}

The majority of respondents indicated that they had previous knowledge of antibiotic agents $(99.7 \%)$ and of their usage $(98.3 \%)$. Only $86.6 \%$ of them, however, correctly identified penicillin as an antibiotic, while $51.8 \%$ did not know whether codeine was an antibiotic or not. While $93.7 \%$ knew that antibiotics should be used in the treatment of bacterial infections, $18.1 \%$ thought that they may also be used in the treatment of viral infections. When these two questions were combined, $75.0 \%$ of respondents correctly stated that antibiotics are effective against bacterial but not against viral infections (table 2).

Of the respondents, $97.2 \%$ had used antibiotics during the past year. Of these medicines, $51 \%$ were obtained through a doctor's prescription. Most of them, $61.8 \%$ of
Table 1 Characteristics of the study population $(n=1042)$ (always put tables outside of text. Insert at end of main text or as separate file)

\begin{tabular}{lc}
\hline Demographics & $\begin{array}{l}\text { Respondents } \\
\mathbf{n}(\%)\end{array}$ \\
\hline Gender & \\
Males & $493(47.3)$ \\
Females & $549(52.7)$ \\
Age groups & \\
$18-20$ & $280(26.9)$ \\
$21-23$ & $599(57.5)$ \\
$24-26$ & $162(15.6)$ \\
Nationality & $1016(97.5)$ \\
Saudi Arabia & $26(2.5)$ \\
Others & \\
University & $592(56.8)$ \\
Umm Alqura & $450(43.2)$ \\
King Abdulaziz & \\
\hline
\end{tabular}

cases, were used for a RTI. In the past year, $87.1 \%$ of respondents had obtained some information on antibiotics from one source or another. Among the top three sources of information cited were doctors $(43.6 \%)$, followed by the internet $(41.2 \%)$ and 'other sources' $(47.2 \%)$, which was the most common answer, ahead of the other choices given to respondents, namely:

Table 2 Respondents' knowledge, beliefs and experiences of antibiotics $(n=1042)$

\begin{tabular}{|c|c|c|}
\hline \multicolumn{2}{|c|}{ Knowledge, beliefs and experiences } & \multirow{2}{*}{$\begin{array}{l}\text { Agree } \\
\text { n (\%) } \\
782(75.0)\end{array}$} \\
\hline Knowledge & $\begin{array}{l}\text { Antibiotics are effective in } \\
\text { treating bacterial but not } \\
\text { viral infections }\end{array}$ & \\
\hline & $\begin{array}{l}\text { Antibiotics are effective in } \\
\text { treating bacterial infections }\end{array}$ & 976 (93.7) \\
\hline & $\begin{array}{l}\text { Antibiotics are effective in } \\
\text { treating viral infections }\end{array}$ & $188(18.1)$ \\
\hline \multirow[t]{7}{*}{$\begin{array}{l}\text { Beliefs and } \\
\text { Experiences }\end{array}$} & $\begin{array}{l}\text { I usually know when I need } \\
\text { antibiotics }\end{array}$ & 717 (68.9) \\
\hline & $\begin{array}{l}\text { My doctor's obligated to } \\
\text { prescribe antibiotics on my } \\
\text { request }\end{array}$ & $129(12.4)$ \\
\hline & $\begin{array}{l}\text { It is easy to obtain } \\
\text { antibiotics }\end{array}$ & 737 (70.9) \\
\hline & $\begin{array}{l}\text { Decisions regarding the } \\
\text { prescription of antibiotics } \\
\text { should only be taken by a } \\
\text { specialist doctor }\end{array}$ & 836 (80.2) \\
\hline & $\begin{array}{l}\text { Doctors should not be } \\
\text { hasty in prescribing } \\
\text { antibiotics }\end{array}$ & $987(95.1)$ \\
\hline & $\begin{array}{l}\text { It is acceptable to stop a } \\
\text { course of antibiotics as } \\
\text { soon as symptoms resolve }\end{array}$ & 225 (21.6) \\
\hline & $\begin{array}{l}\text { Bacteria can become } \\
\text { resistant to antibiotics }\end{array}$ & $990(95.0)$ \\
\hline
\end{tabular}


Table 3 Respondents' perceived need for antibiotic treatment, perceived need to consult a doctor for respiratory tract symptoms and perceived need for antibiotic treatment for RTIs $(n=1042)$

\begin{tabular}{lll}
\hline Symptoms and RTIs & $\begin{array}{l}\text { Perceived need for antibiotic } \\
\text { treatment (always/often) } \\
\mathbf{n}(\%)\end{array}$ & $\begin{array}{l}\text { Perceived need to consult } \\
\text { a doctor (always/often) } \\
\mathbf{n}(\%)\end{array}$ \\
\hline $\begin{array}{l}\text { Symptoms } \\
\text { Throat congestion }\end{array}$ & $383(36.8)$ & $274(26.3)$ \\
Nose congestion with headache & $219(21.0)$ & $232(22.3)$ \\
Cough with transparent phlegm & $139(13.4)$ & $213(20.4)$ \\
Cough with yellow/green phlegm & $753(72.3)$ & $537(51.6)$ \\
Cough with fever & $607(58.3)$ & $449(43.1)$ \\
Cough lasting more than 2 weeks & $615(59.1)$ & $628(60.3)$ \\
RTls & $153(14.7)$ & NA \\
Common cold and or flu & $664(63.9)$ & \\
Acute bronchitis & $861(82.9)$ & \\
Pneumonia & &
\end{tabular}

pharmacists, drugstores, leaflets/publications related to a disease or a health condition, medicine notice/leaflet and the media (television, newspapers or magazines). Those who answered 'other sources' reported that medical textbooks were their source of knowledge.

Where RTI symptoms were mentioned, the perceived need to consult with a doctor ranged from $60.3 \%$ for a continuous cough lasting 2 weeks, to $20.4 \%$ for a cough with clear phlegm. On the other hand, the perceived need for taking antibiotics was $72.3 \%$ for a cough with yellow phlegm, and $13.4 \%$ for a cough with clear phlegm (table 3).

\section{Variables associated with accurate knowledge of antibiotic effectiveness}

Bivariate analysis of the data indicated that women had better knowledge of the effectiveness of antibiotics against bacteria but not against viruses (table 4). Knowledge of the effectiveness of antibiotics steadily rose with the year of study. Finally, those who acknowledged the emergence of developing bacterial resistance were more likely to have accurate knowledge on antibiotic effectiveness.

On the other hand, no significant associations were noted between knowledge of the effectiveness of antibiotics and previous use of antibiotics $(\mathrm{p}=0.097)$, previous prescription of antibiotics within the year $(\mathrm{p}=0.987)$ or previous prescription of antibiotics for respiratory infections within the year $(p=0.457)$.

\section{DISCUSSION}

In this large questionnaire study, we identified that Saudi Arabian medical students have extensive experience in using antibiotics for URTI themselves, but knowledge on antibiotic effectiveness vary widely with differences in gender and years of experience as medical student. Practices to obtain antibiotics without a prescription are also common among medical students themselves.

\section{LIMITATIONS AND STRENGTHS}

The study's limitations lay in that it was conducted among medical students in two big universities in the western region of Saudi Arabia. As such, the study population inherently showed a high knowledge of the use of antibiotics. Students from other disciplines as well as the population at large may have different levels of knowledge in relation to the subject at hand. Currently, a study is being conducted to evaluate the knowledge, attitudes and behaviour regarding the use of antibiotics among the public in Saudi Arabia. In the future, it would be interesting to expand the study to include rural communities from different regions of Saudi Arabia to be able to formulate specific recommendations to target and inform the public.

On the other hand, this study managed to include more than 1000 participants, which marks the first time for a study of such scale to be conducted in Saudi Arabia. This is an important study as it sheds the light on the knowledge, attitude and behaviours of a highly

Table 4 Factors significantly associated with accurate knowledge of antibiotics' effectiveness (782 of 1042 who had accurate knowledge)

\begin{tabular}{|c|c|c|c|}
\hline Factors & Accurate knowledge & OR & p Value \\
\hline \multicolumn{4}{|l|}{ Gender } \\
\hline Males & 349 (70.8\%) & - & 0.003 \\
\hline Females & $433(78.9 \%)$ & 1.540 & \\
\hline \multicolumn{4}{|l|}{ Study year } \\
\hline $1 \mathrm{st}$ & 22 (28.6\%) & - & 0.001 \\
\hline 2nd & 95 (54.6\%) & 3.006 & \\
\hline 3rd & $130(65.7 \%)$ & 4.779 & \\
\hline 4th & $158(84.9 \%)$ & 14.107 & \\
\hline 5th & 195 (92.4\%) & 30.469 & \\
\hline 6th & $182(92.9 \%)$ & 32.500 & \\
\hline \multicolumn{4}{|c|}{ Bacterial resistance to antibiotics } \\
\hline Agree & 764 (77.2\%) & 6.385 & 0.000 \\
\hline Disagree & $18(34.6 \%)$ & - & \\
\hline
\end{tabular}


specialised section of the Saudi community, namely, future doctors, who will be responsible for the prescription of antibiotics for years to come.

\section{Knowledge, attitudes and practices}

The data on the use of antibiotics against bacterial and not viral infections, and on the need to complete the course of treatment to reduce antimicrobial resistance, are much higher than what has been reported in a survey on the public in the Netherlands. ${ }^{8}$ The medical background of our participants may account for those differences. Those who answered incorrectly were mostly first year students who had not received courses related to antibiotics, similar to findings of a large study among Chinese students. ${ }^{9}$ The results on the need for careful prescription of antibiotics by a physician are in contrast to those of an Italian study that reported that $22.7 \%$ of their respondents were willing to take an antibiotic without doctor's prescription. ${ }^{10}$ Again, the medical background of our study population could explain this. Bacterial resistance to antibiotics was indicated among our study group and only a small percentage thought it acceptable to stop the course of antibiotics as soon as the symptoms subside, and the participants were aware of the adverse effects associated with the excessive and improper use of antibiotics in the emergence of bacterial resistance.

Obtaining antibiotics over the counter, without a physician's prescription, has been a common practice in developing countries and is consistent with other studies. ${ }^{11}$ The familiarity of our respondents with the different antibiotics is due to their medical background and is contrary to the results from an Italian study that indicated some superficiality in the knowledge of antibiotics and resistance. ${ }^{10}$ In a study conducted in the UK, final year medical students were given the names 'Ciproxin' and 'ciprofloxacin' as an example, and were asked to name six generic or approved antibiotics by their proprietary name. Sixty per cent of them only knew the generic names for Augmentin and Fucidin, $40 \%$ were correct on Flagyl and $10 \%$ on Zinacef, but none had the correct generic name for either Targocid or Magnapen. ${ }^{12}$ In another study conducted in Malaysia, also on final year medical and pharmacology students, diphenhydramine was correctly identified by $97 \%$ of the students as the antibiotic used for treatment of URIs, while only $75.6 \%$ correctly identified that cefotaxime belonged to third-generation cephalosporins. ${ }^{13}$ The patient's pressure on their doctors to prescribe antibiotics were similar to others. ${ }^{14}$ This is especially true among the middle-income and low-income settings, as reported in a study in Peru, ${ }^{15}$ and among parents and paediatricians in Venezuela, where $87 \%$ of doctors felt pressured by parents into prescribing antibiotics. ${ }^{16}$

Health seeking behaviour rates for symptoms of RTI and the associated estimated necessity for antibiotics were slightly lower than what has been reported elsewhere and again a reflection of the medical background of the study population. ${ }^{8}$ Our respondents thought that antibiotics should always be prescribed when experiencing cough with yellow/clear phlegm. This is a misconception, and a reflection of wrong knowledge among our respondents, which is not consistent with the results obtained by others. ${ }^{8}$

\section{Other studies in low-income and middle-income countries}

Studies conducted in many developing countries, including Palestine and southwest Nigeria, have indicated that people rely on the advice of their 'medical' friends to self-medicate. ${ }^{17} 18$ In addition, in many instances, people reported copying a doctor's prescription without a second consultation with a physician or without the need for a fresh prescription. In contrast to this, respondents in this study stated that they relied on their doctors for the prescription of antibiotics. Also, the same was reported in other published studies. ${ }^{11}$

Being in the medical field, participants to this study had a good background in relation to the time to start antibiotics treatment. These findings are consistent with what has been reported by others. ${ }^{9} 1920$

Older students were more likely to be knowledgeable in relation to antibiotics' effectiveness. This is consistent with what has been reported by others in a study among Chinese medical students, which indicated that the students' knowledge improved as they progressed in their study, attaining the highest scores at third and fourthyears, suggesting that the medical curriculum enhanced their understanding of antibiotics use. Similarly, their attitude on the use of antibiotics was only slightly improved (year 4) over the same period with a clearer recognition of antibiotic abuses and development of drug resistance in bacteria. ${ }^{9}$ The reason behind this could be that courses on medical microbiology are not given during the first year. Another reason could be that other relevant courses, such as pharmacology, internal medicine and epidemiology, also are not provided to students during their first year of medical school. The increase of knowledge of participants with their years of study would indicate that their cumulative curricula enhanced their knowledge about antibiotics usage and the dangers of encountering resistance. This is contrary to the findings of a study conducted on house staff physicians at the Johns Hopkins University Hospital in Baltimore, which showed that physicians had a suboptimal knowledge about antimicrobials, and their knowledge was not enhanced over the course of their training. ${ }^{21}$

The results showed that young women had more accurate knowledge of antibiotics' effectiveness than young men did $(p=0.003)$. In Saudi society, women are more inclined to spend time with their mothers and be involved in raising children. As such, they become more aware of the medications children take and the diseases they encounter throughout their childhood. This is consistent with what has previously been reported by others who also found that women consult more frequently, often with their children, and therefore receive more accurate information on antibiotics; however, the finding 
that women had more accurate knowledge was independent of having children in the household in that study. ${ }^{8}$

\section{CONCLUSION}

The knowledge on antibiotic effectiveness varies widely with differences in gender and years of experience as medical student in this large study among medical students in Saudi Arabia. Self-medication of antibiotics without a prescription is common among students in Saudi Arabia, which is worrying. The results may shed important light on areas for improvement in the medical curriculum as well as antibiotic practices of medical students themselves.

\section{Author affiliations}

${ }^{1}$ Special Infectious Agents Unit, King Fahd Medical Research Center, King Abdulaziz University, Jeddah, Saudi Arabia

${ }^{2}$ Obstetrics and Gynecology Department, King Abdulaziz Medical City, National Guard Health Affair, Riyadh, Saudi Arabia

${ }^{3}$ Manchester, UK

${ }^{4}$ Department of Pediatric, King Fahad Armed Forces Hospital, Jeddah, Saudi Arabia

${ }^{5}$ Medical School, Umm Alqura University, Makkah, Saudi Arabia

${ }^{6}$ Department of Family Medicine, National Guard Hospital, Jeddah, Saudi Arabia

${ }^{7}$ Department of Pediatric, National Guard Hospital, Jeddah, Saudi Arabia

${ }^{8}$ Biology Department, King Abdulaziz University, Jeddah, Saudi Arabia

${ }^{9}$ Department of Animal and Veterinary Sciences, American University of Beirut, Lebanon; Adjunct to Biochemistry Department, Faculty of Science and Production of Bioproducts for Industrial Application Research Group, King Abdulaziz Univeristy, Jeddah, Saudi Arabia

${ }^{10}$ King Fahd Medical Research Center, Jeddah, Saudi Arabia

${ }^{11}$ Department of Gastroenterology, Faculty of Medicine, King Abdulaziz University, Jeddah, Saudi Arabia

${ }^{12}$ Biochemistry Department, Faculty of Science and Experimental Biochemistry Unit, King Fahd Medical Research Center, Jeddah, Saudi Arabia

${ }^{13}$ Department of Interdisciplinary Social Science, Utrecht University, Utrecht, The Netherlands

${ }^{14}$ Drug Metabolism Unit, King Fahd Medical Research Center, Jeddah, Saudi Arabia

${ }^{15}$ Department of Family Medicine, School of Primary Care and Public Health (CAPHRI), Maastricht University, Maastricht, The Netherlands

Competing interests None declared.

Ethics approval The University Ethical Committee.

Provenance and peer review Not commissioned; externally peer reviewed.

Data sharing statement No additional data are available.

Open Access This is an Open Access article distributed in accordance with the Creative Commons Attribution Non Commercial (CC BY-NC 4.0) license, which permits others to distribute, remix, adapt, build upon this work noncommercially, and license their derivative works on different terms, provided the original work is properly cited and the use is non-commercial. See: http:// creativecommons.org/licenses/by-nc/4.0/

\section{REFERENCES}

1. Eccles MP, Grimshaw JM, Johnston M, et al. Applying psychological theories to evidence-based clinical practice: identifying factors predictive of managing upper respiratory tract infections without antibiotics. Implement Sci 2007;2:26.

2. Sabra SM, Omar SR, Abdel-Fattah MM. Surveillance of Some common infectious diseases and evaluation of the control measures used at Taif, KSA (2007-2011). Middle-East J Sci Res 2012;11:709-17.

3. Alghamdi AA, Alamoudi OS, Ghabrah TM. Pattern of infectious diseases in the western region of Saudi Arabia; a study of 495 hospitalized patients. J King Abdulaziz Univ Med Sci 2009;16:3-15.

4. Chowdhury MN. Empiric therapy of common bacterial infections in Saudi Arabia; a review. J Hyg Epidemiol Microbiol Immunol 1992;36:63-84.

5. Gonzales R, Malone DC, Maselli JH, et al. Excessive antibiotic use for acute respiratory infections in the United States. Clin Infect Dis 2001;33:757-62.

6. Heikkinen T, Järvinen A. The common cold. Lancet 2003;361:51-9.

7. Alumran $\mathrm{A}, \mathrm{Hou} \mathrm{XY}$, Hurst $\mathrm{C}$. Assessing the overuse of antibiotics in children in Saudi Arabia: validation of the parental perception on antibiotics scale (PAPA scale). Health Qual Life Outcomes 2013;11:1-8.

8. Cals JWL, Boumans D, Lardinois RJM, et al. Public beliefs on antibiotics and respiratory tract infections: an internet-based questionnaire study. Br J Gen Pract 2007;57:942-7.

9. Huang $\mathrm{Y}, \mathrm{Gu} J$, Zhang M, et al. Knowledge, attitude and practice of antibiotics: a questionnaire study among 2500 Chinese students. BMC Med Educ 2013;13:163.

10. Napolitano F, Izzo MT, Di Giuseppe G, et al. Public knowledge, attitudes, and experience regarding the use of antibiotics in Italy. PLOS ONE 2013;8:e84177.

11. Widayati A, Suryawati S, de Crespigny C, et al. Beliefs about the use of nonprescribed antibiotics among people in Yogyakarta City, Indonesia: a qualitative study based on the theory of planned behavior. Asia Pac J Public Health 2015;27:NP402-13.

12. Wright EP, Jain P. Survey of antibiotic knowledge amongst final year medical students. J Antimicrob Chemother 2004;53:550-1.

13. Jamshed $S Q$, Elkalmi $\mathrm{R}$, Rajiah $\mathrm{K}$, et al. Understanding of antibiotic use and resistance among final-year pharmacy and medical students: a pilot study. J Infect Dev Ctries 2014;8:780-5.

14. Thriemer K, Katuala Y, Batoko B, et al. Antibiotic prescribing in DR Congo: a knowledge, attitude and practice survey among medical doctors and students. PLOS ONE 2013;8:e55495.

15. García C, Llamocca LP, García K, et al. Knowledge, attitudes and practice survey aboutantimicrobial resistance and prescribing amongphysicians in a hospital setting in Lima, Peru. BMC Clin Pharmacol 2011;11:18.

16. ML NL, Martin A. Influencia de los padres en la prescripcion de antibioticos hecha por los pediatras. Arch Venez Pueric Pediatr 2002;65:21-7.

17. Sapkota AR, Coker ME, Goldstein RER, et al. Self-medication with antibiotics for the treatmentof menstrual symptoms in southwest Nigeria: across-sectional study. BMC Public Health 2010;10:610.

18. Sawalha AF. Self-medication with antibiotics: a study in Palestine. Int J Risk Saf Med 2008;20:213-22.

19. Dyar OJ, Pulcini C, Howard P, et al. European medical students: a first multicentre study of knowledge, attitudes and perceptions of antibiotic prescribing and antibiotic resistance. J Antimicrob Chemother 2014;69:842-6.

20. Bala R, Singh H, Kaur K. Knowledge and attitude towards antimicrobial self medication usage: a cross sectional study among medical and nursing students. Int $J$ Basic Clin Pharmacol 2013;2:428-32.

21. Srinivasan A, Song X, Richards A, et al. A survey of knowledge, attitudes, and beliefs of house staff physicians from various specialties concerning antimicrobial use and resistance. Arch Intern Med 2004;164:1451-6. 